\title{
Métodos de inoculação de Colletotrichum lindemuthianum em sementes de feijão e danos em plântulas
}

\author{
Patricia Migliorini 1,2* \\ Keilor da Rosa Dorneles ${ }^{1}$ \\ Gustavo Fonseca Rodrigues ${ }^{1}$ \\ Gabriele de Paula ${ }^{1}$ \\ Lilian Vanussa Madruga de Tunes ${ }^{1,2}$ \\ ${ }^{1}$ Faculdade de Agronomia Eliseu Maciel, Universidade Federal de Pelotas \\ CEP 96010-610, Pelotas - RS, Brasil \\ ${ }^{2}$ Programa de Pós-Graduação em Ciência \& Tecnologia de Sementes \\ Universidade Federal de Pelotas, Pelotas - RS, Brasil \\ * Autor para correspondência \\ pati.migliorini@gmail.com
}

Submetido em 28/05/2016

Aceito para publicação em 10/01/2017

\section{Resumo}

A antracnose causada pelo fungo Colletotrichum lindemuthianum (Sacc. \& Magnus) Scrib. é uma das doenças mais sérias da cultura do feijão. Técnicas de inoculação são importantes para avaliações de resistência de genótipos e de métodos de controle em fases iniciais do desenvolvimento de plântulas. Diante da necessidade de se obter plântulas infectadas, o presente trabalho teve por objetivo testar diferentes métodos de inoculação de $C$. lindemuthianum em sementes de feijão e verificar o impacto na emergência e no desenvolvimento inicial das plântulas. Foram utilizadas sementes da cv. BRS Expedito, as quais foram inoculadas pelos métodos de suspensão de esporos, de contato com o patógeno em meio com restrição hídrica e de inoculação com discos de BDA contendo micélio e esporos do fungo no substrato. O delineamento experimental foi inteiramente casualizado com oito repetições. Foram feitas avaliações de emergência, comprimento de parte aérea, massa seca de parte aérea e a incidência de sintomas da doença em folha e no hipocótilo. Os métodos de inoculação utilizados foram eficientes para causar infecção do patógeno em plântulas de feijão, sem afetar a emergência, destacando o método de contato com o patógeno em meio com restrição hídrica como o mais eficaz.

Palavras-chave: Antracnose; Contaminação; Desenvolvimento inicial; Feijão; Infecção

\section{Abstract}

Inoculation methods of Colletotrichum lindemuthianum in seeds of Phaseolus vulgaris. Anthracnose caused by Colletotrichum lindemuthianum (Sacc. \& Magnus) Scrib. is one of the most serious diseases of bean crops. Inoculation techniques are important to evaluate the resistance of genotypes and control methods at early stages of seedling development. Due to the need for infected seedlings, the objective of the present study was to test different inoculation methods of $C$. lindemuthianum on bean seeds to verify the the impact on the emergence and early development of seedlings. Seeds of BRS Expedito were inoculated by spore suspension, 
contact with the pathogen in a water restricted medium, and with PDA discs containing mycelium and spores of the fungus. The experimental design was completely randomized with eight repetitions. Emergence, shoot length and dry mass, and incidence of symptoms of the disease on the hypocotyl and leaf were evaluated. The inoculation methods were effective at causing the infection of the pathogen in the bean seedlings, without affecting emergence, and contact with the pathogen in a water restricted medium was the most effective method.

Key words: Anthracnose; Bean; Initial development; Contamination; Infection

\section{Introdução}

O feijão (Phaseolus vulgaris L.) é uma planta pertencente à família das Leguminosae, que se destaca pela importância nutricional, social e econômica, sendo a principal fonte de proteínas para as populações de baixa renda. No Brasil estima-se que a área plantada de feijão em 2015/2016 tenha chegado a 3.047,5 mil hectares, com produtividade média prevista de 1.086 $\mathrm{kg} / \mathrm{ha}^{-1}$, resultando uma produção esperada de 3.309,3 mil de toneladas (CONAB, 2016).

Essa cultura está sujeita a um elevado número de doenças, sendo que os patógenos, em sua maioria, são transportados ou/e transmitidos por sementes. Entre as doenças mais importantes da cultura está a antracnose, causada pelo fungo Colletotrichum lindemuthianum, os sintomas podem ser observados em plântulas e também em toda parte aérea da planta. O fungo sobrevive em restos de cultura, mas as sementes constituem sua via de sobrevivência e disseminação mais importante, podendo servir como fonte de inóculo para infecções primárias (BIANCHINI et al., 2005).

Metodologias de inoculação são primordiais para o desenvolvimento de pesquisas relacionadas à avaliação de resistência genética e ao desenvolvimento de métodos de controle (GALLI et al., 2007; CORRÊA et al., 2008; GARCIA; JULIATTI, 2012; JUNGES et al., 2015). Os métodos de inoculação devem garantir a reprodução e expressão dos sintomas típicos da doença nas plântulas ou plantas (FALCÃO et al., 2005; SOUSA et al., 2008). No entanto, os diferentes métodos de inoculação, tempo e temperatura podem apresentar respostas desiguais para cada cultura e influenciar diretamente na infecção e no desenvolvimento de sintomas e sinais do patógeno (ARAÚJO et al., 2006). Técnicas de inoculação devem garantir a infecção de sementes sem comprometer o potencial germinativo e a emergência das plântulas, para garantir possíveis avaliações futuras (SOUSA et al., 2008).

Os métodos utilizados para a inoculação em sementes podem ser realizadas por meio da imersão das sementes em suspensão de esporos (SOUSA et al., 2008; PEDROSO et al., 2010), do contato da semente com a colônia fúngica desenvolvida em meio de cultura batata-dextrose-ágar (BDA) ou/e com o emprego de condicionamento osmótico (SOUSA et al., 2008; REY et al., 2009; PEDROSO et al., 2010; BOTELHO et al., 2013; REIS et al., 2014; VENTUROSO et al., 2015) e também pela contaminação do solo/substrato com discos de BDA contendo a colônia fúngica ou com grãos de cereais colonizados (FALCÃO et al., 2005). No entanto, nem sempre é possível atingir níveis satisfatórios de infecção, principalmente pelo fato da limitação de alguns testes terem de contaminar ou/e infectar a semente ou a plântula.

Dessa forma, o presente trabalho teve por objetivo testar diferentes métodos de inoculação de Colletotrichum lindemuthianum em sementes de feijão e verificar o impacto na emergência e no desenvolvimento inicial das plântulas.

\section{Material e Métodos}

O experimento foi conduzido no Laboratório de Patologia de Sementes da Faculdade de Agronomia "Eliseu Maciel" (FAEM), da Universidade Federal de Pelotas - RS. Foram utilizadas sementes da cultivar BRS Expedito safra 2014/2015, que apresentavam germinação de $92 \%$, e no teste de sanidade foram observadas porcentagens de 79,5\% de incidência de Fusarium sp.; 20,5\% para Aspergillus sp.; 19\% para Alternaria sp.; 2\% para Cladosporium sp. e 0,5\% para Collethochum sp. Assim, para eliminar os fungos contaminantes presentes na superfície da semente, elas foram previamente 
desinfestadas com álcool 70\% e hipoclorito de sódio a $1 \%$ por um minuto cada; em seguida, foram feitas três lavagens rápidas, em água destilada e esterilizada, e secas em condições de ambiente de laboratório.

O fungo patogênico Colletotrichum lindemuthianum utilizado no estudo foi isolado a partir de fragmentos de folhas e vagens de plantas de feijão sintomáticas. Os fragmentos foram esterilizados e mantidos em ambiente estéril até a secagem, sendo, a seguir, colocados sobre meio de cultura Mathur (MATHUR et al., 1950) e incubados a $20^{\circ} \mathrm{C} \pm 1^{\circ} \mathrm{C}$. Após o crescimento, o patógeno foi repicado para placas de Petri contendo meio de cultura BDA (batata, dextrose e ágar), até a obtenção da cultura pura.

Os diferentes métodos de inoculação em sementes foram constituídos de:

\section{Método de contato com o patógeno em meio de cultura com restrição hídrica}

O meio de cultura contendo BDA modificado (restrição hídrica) com soluto de sacarose no potencial hídrico -0,6 $\mathrm{MPa}$ foi autoclavado e posteriormente vertido em placas de Petri de $9 \mathrm{~cm}$ de diâmetro (REY et al., 2009). Discos com 7 mm de diâmetro, repicados da colônia contendo micélio e esporos do isolado, foram transferidos para as placas e estas incubadas em câmara crescimento por quinze dias, a temperatura de $20^{\circ} \mathrm{C} \pm$ $1^{\circ} \mathrm{C}$ e com fotoperíodo de $12 \mathrm{~h}$.

Em cada placa que estava completamente colonizada pelo fungo foi depositada e distribuída aleatoriamente trinta sementes de feijão, levemente prensadas sobre o meio e ficando em contato com o fungo por $48 \mathrm{~h}$, em temperatura de $20^{\circ} \mathrm{C}$ e fotoperíodo de $12 \mathrm{~h}$. Em seguida, as sementes foram removidas e armazenadas em temperatura controlada de $20^{\circ} \mathrm{C}$ por $48 \mathrm{~h}$.

\section{Método com suspensão de esporos}

O fungo foi cultivado em meio BDA e incubado por 15 dias em câmara de crescimento com temperatura de $20^{\circ} \mathrm{C} \pm 1^{\circ} \mathrm{C}$ e fotoperíodo de $12 \mathrm{~h}$. Após esse período, foram adicionados $15 \mathrm{~mL}$ de água destilada e esterilizada por placa e, com auxílio de um pincel esterilizado, homogeneizou-se a massa de esporos. Em seguida, foi utilizada gaze para a retirada de impurezas, como meio de cultura ou pedaços da colônia. Posteriormente, a concentração foi ajustada para $4 \times 10^{5}$ esporos por $\mathrm{mL}$, com a câmara de Neubauer.

Para cada $40 \mathrm{~g}$ de sementes foram adicionados 10 $\mathrm{mL}$ da suspensão, as sementes permaneceram embebidas na suspensão por 5 minutos, quando foi drenado o excedente de água e as sementes postas para secar sobre papel filtro em temperatura controlada de $20^{\circ} \mathrm{C}$ por $48 \mathrm{~h}$.

\section{Inoculação do substrato com discos de BDA contendo micélio e esporos do fungo}

Para infestação do substrato, cinco discos de 5 $\mathrm{mm}$ de micélio foram retirados de colônias cultivadas em meio BDA, mantidas em câmara de crescimento com temperatura de $20^{\circ} \mathrm{C} \pm 1{ }^{\circ} \mathrm{C}$ e fotoperíodo de $12 \mathrm{~h}$ durante quinze dias. Os discos foram depositados em copos plásticos de $200 \mathrm{~mL}$, contendo substrato vermiculita autoclavada, e previamente umedecidos com água destilada e esterilizada, sendo posteriormente acondicionados em sacos plásticos devidamente fechados e levados para a câmara de crescimento por sete dias, a temperatura de $20^{\circ} \mathrm{C} \pm 1{ }^{\circ} \mathrm{C}$ e com fotoperíodo de $12 \mathrm{~h}$.

Como testemunha dos tratamentos (controle), utilizaram-se sementes de feijão não inoculadas. Posteriormente aos procedimentos de inoculação do substrato e das sementes pelo método de contato direto e suspensão de esporos, realizaram-se as seguintes avaliações:

\section{Emergência}

Realizada com 40 sementes por tratamento, distribuídas em oito repetições de cinco sementes, estas foram semeadas na profundidade de $2 \mathrm{~cm}$, em copos plásticos de $200 \mathrm{~mL}$ contendo substrato de vermiculita esterilizada. O substrato foi umedecido com água, obedecendo à capacidade de campo de $60 \%$ da retenção, e mantido úmido sempre que necessário. Os tratamentos contendo diferentes métodos de inoculação foram 
mantidos em ambiente controlado com temperatura de $20^{\circ} \mathrm{C} \pm 1^{\circ} \mathrm{C}$ e fotoperíodo de $12 \mathrm{~h}$. A avaliação foi realizada aos 10 (E10) e aos 15 (E15) dias após a semeadura (DAS), sendo consideradas plântulas emergidas aquelas com folíolos primários expandidos, e os resultados expressos em porcentagem (NAKAGAWA, 1994).

\section{Comprimento de parte aérea}

Realizado conjuntamente com o teste de emergência aos 10 (CPA10) e 15 (CPA15) DAS, todas as plântulas normais das repetições de cada tratamento foram avaliadas pela medida do início da parte aérea até o ápice da folha mais nova, mensurada com auxílio de uma régua graduada em centímetros, sendo os resultados expressos em cm/plântula ${ }^{-1}$ (NAKAGAWA, 1999).

\section{Massa seca de parte aérea (MSPA)}

Após a contagem final do teste de emergência (E15), parte aérea das plântulas normais de cada tratamento e repetição foram coletadas e postas em sacos de papel, sendo posteriormente alocadas em estufa regulada a $70^{\circ} \mathrm{C}$ para secar, até atingir peso constante, obtido em $72 \mathrm{~h}$. Após, estas foram pesadas e os resultados expressos em gramas/plântula-1 (NAKAGAWA, 1999).

\section{Incidência de doença}

A avaliação foi realizada aos $15 \mathrm{DAS}$, foram observados sintomas no hipocótilo e na folha de todas as plântulas das repetições dos tratamentos, sendo os resultados expressos em porcentagem de incidência de sintomas em folhas (IF) e de incidência no hipocótilo (IH).

\section{Análise estatística e delineamento experimental}

O delineamento experimental utilizado foi inteiramente casualizado, sendo constituído por quatro tratamentos e oito repetições. As variáveis analisadas foram submetidas à análise de variância (ANOVA), e as médias dos tratamentos, comparadas pelo teste de Tukey $(p \leq 0.05)$. Os dados não normais (porcentagem) foram transformados segundo arc sem $\sqrt{ } \mathrm{x} / 100$. As análises foram realizadas com auxílio do programa estatístico SISVAR versão 5.0 (FERREIRA, 2007).

\section{Resultados}

Na Tabela 1, observa-se que não houve diferenças significativas para emergência aos 10 e 15 dias após a semeadura de sementes de feijão submetidas a diferentes métodos de inoculação de Colletotrichum lindemuthianum. Resultados esses demonstram de forma eficiente que a inoculação do patógeno em sementes de feijão sobre diferentes formas de contaminação não comprometem a emergência das plântulas.

Os resultados referentes ao comprimento de parte aérea aos 10 e 15 dias após a semeadura (DAS) evidenciam que os métodos de contato e de suspensão

TABELA 1: Emergência de plântulas de feijão aos 10 (E10) e 15 (E15) dias após a semeadura (DAS), comprimento de parte aérea aos 10 (CPA10) e 15 (CPA15) DAS e massa seca de parte aérea (MSPA), em função de diferentes métodos de inoculação de Colletotrichum lindemuthianum em sementes. Pelotas, 2016.

\begin{tabular}{lccccc}
\hline \multirow{2}{*}{ Tratamento } & E10 & E15 & CPA10 & CPA15 & MSPA \\
\cline { 2 - 6 } & & $-----(\%)----$ & $-----(c m /$ plântula) ----- & $(\mathrm{g} /$ plântula $)$ \\
\hline Testemunha & $91^{\text {ns* }}$ & $91^{\text {ns }}$ & $13,36 \mathrm{ab}$ & $16,02 \mathrm{a}$ & $0,094^{\text {ns }}$ \\
Contato & 85 & 89 & $11,24 \mathrm{~b}$ & $13,03 \mathrm{~b}$ & 0,087 \\
Disco & 91 & 91 & $13,53 \mathrm{a}$ & $16,21 \mathrm{a}$ & 0,083 \\
Suspensão & 83 & 83 & $13,13 \mathrm{ab}$ & $15,04 \mathrm{ab}$ & 0,087 \\
\hline Média & 88 & 88 & 12,53 & 15,07 & 0,087 \\
\hline CV (\%) & 8,27 & 7,8 & 13 & 10,83 & 15,85 \\
\hline
\end{tabular}

*Médias seguidas pela mesma letra minúscula na coluna não diferem entre si a $5 \%$ de probabilidade pelo teste de Tukey. ${ }^{\text {ns: }}$ não significativo. Testemunha: sementes não inoculadas; Disco: inoculação do substrato com discos de BDA contendo micélio e esporos do fungo; Contato: método de contato com o patógeno em meio de cultura BDA com restrição hídrica; Suspensão: método com suspensão de esporos. 
de esporos comprometeram o desenvolvimento, produzindo plântulas menos vigorosas e confirmando os efeitos prejudiciais do patógeno sobre as sementes de feijão (Tabela 1). Aos 10 DAS apenas o tratamento de contato diferiu estatisticamente do método de discos de micélio; já aos 15 DAS o mesmo tratamento continuou mostrando resultados inferiores aos da testemunha e aos do método de discos, o que aponta a capacidade do $C$. lindemuthianum em causar danos.

Para a variável massa seca de parte aérea (Tabela 1), os diferentes métodos de inoculação não apresentaram diferença estatística entre os tratamentos. O mesmo foi observado por Rey et al. (2009) em plântulas de feijão oriundas de sementes inoculadas e em testemunha não inoculada com diferentes raças de $C$. lindemuthianum.

Os diferentes métodos de inoculação como o de contato com o patógeno em meio de cultura com restrição hídrica, método com suspensão de esporos e a inoculação do substrato com discos de BDA contendo micélio e esporos do fungo foram todos semelhantes entre si e superior à testemunha (sem a presença do patógeno) para a incidência de sintomas da doença no hipocótilo e em folha (Figura 1).

As lesões observadas da doença no hipocótilo foram de sentido longitudinal, alongadas, deprimidas e de coloração marrom escura, e a incidência dos sintomas da doença variou de $31 \%, 33 \%$ e $60 \%$ para os métodos de discos de BDA, de suspensão e de contato, respectivamente, não sendo observados sintomas no tratamento testemunha. Em folhas foram observadas lesões necróticas de cor marrom escura ao longo das nervuras na parte inferior da folha, cuja incidência foi superior a $85 \%$ entre os diferentes métodos de inoculação, no entanto, somente o tratamento testemunha diferiu estatisticamente dos demais, onde foi observada uma incidência de sintomas em 11\% nas folhas (IF). Esses resultados demonstram que apesar da desinfestação das sementes o Colletotrichum sp., que apresentava uma incidência natural de $0,5 \%$ antes da desinfestação, foi um bom agente de transmissão mesmo em baixas porcentagens.

\section{Discussão}

Diferentes meios de inoculação são utilizados para possibilitar a infecção de sementes e plântulas com diferentes níveis de inóculo, capazes de influenciar na germinação das sementes e na taxa de transmissão

FIGURA 1: Incidência de sintomas da doença no hipocótilo (IH) e incidência de sintomas na folha (IF) em função de diferentes métodos de inoculação de Colletotrichum lindemuthianum em sementes. Pelotas, 2016.

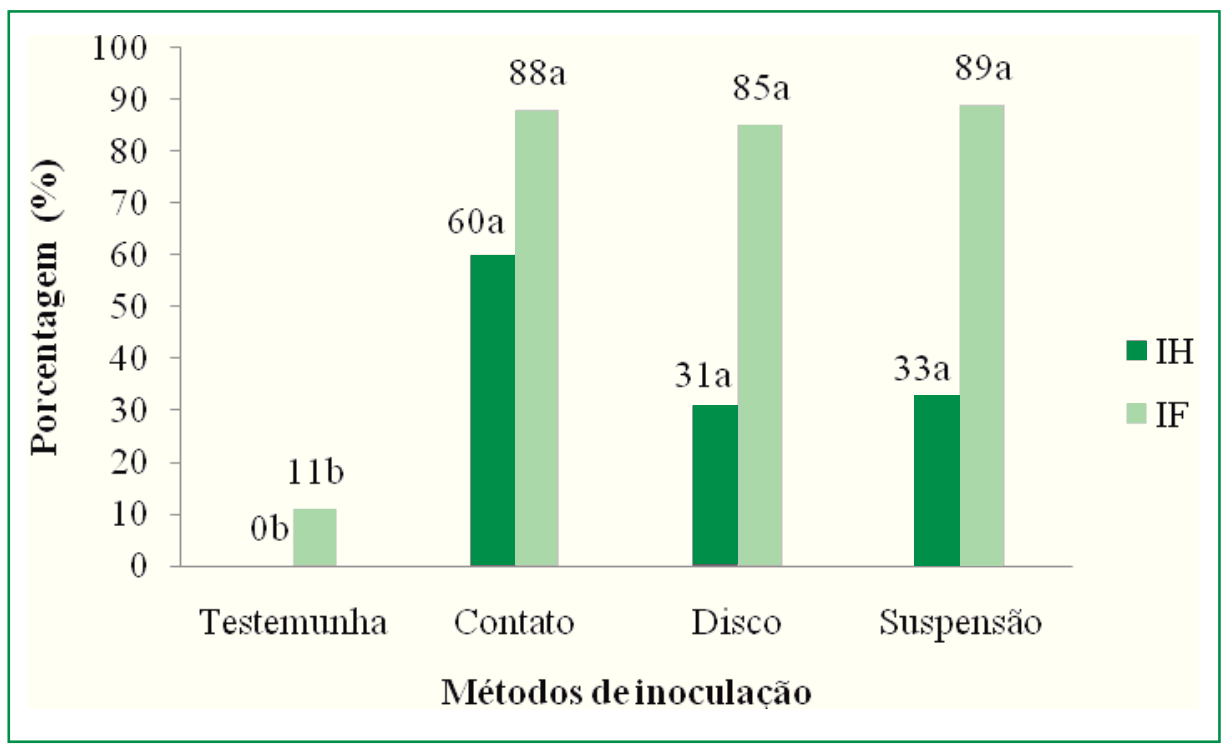


de patógenos para as plantas, no entanto, algumas técnicas comprometem o desempenho das sementes durante a realização do teste, inviabilizando-as para as futuras avaliações. No trabalho foi observado que o C. lindemuthianum, nas suas diferentes formas de inoculação, apresentou sintomas nas plântulas tanto em folhas como no hipocótilo, sem comprometer a emergência das sementes.

Trabalhos realizados por Galli et al. (2007), com a inoculação de Colletotrichum truncatum em sementes de soja pelo método de contato em meio BDA, verificaram que durante o período de $40 \mathrm{~h}$ essa técnica provocou morte das sementes e plântulas de soja. O maior tempo de exposição da semente ao patógeno resultou em um maior nível de potencial do inóculo nas sementes, comprometendo drasticamente o desenvolvimento do embrião. O mesmo foi observado por Barrocas et al. (2014) em sementes de algodão com o fungo C. gossypii var. cephalosporioides.

Com a utilização de suspensão de esporos, Pedroso et al. (2010) observaram em sementes de salsa que os patógenos Alternaria alternata e Alternaria dauci aumentaram o número de plântulas defeituosas e de morte das sementes. Falcão et al. (2005) não encontraram efeito na mortalidade de plântulas de soja pra Sclerotinea sclerotiorum e Sclerotium rolfsii através do método de contaminação do solo por meio de discos de micélio, o mesmo resultado foi encontrado no presente trabalho. Não foi possível observar diferenças significativas na emergência das plântulas entre os tratamentos, porém efeitos prejudiciais durante os estádios iniciais de desenvolvimento das plântulas de feijão foram observadas quando as sementes foram inoculadas pelo método de contato direto, no entanto, esse tratamento não diferiu do método de suspensão de esporos.

O nível de infecção nas sementes contaminadas pode comprometer o desempenho das plântulas, como observado por Pedroso et al. (2010) em salsa, com a inoculação de Alternaria sp. em sementes através dos métodos de suspensão e de contato. Em algodão, a suspensão de esporos de Fusarium oxysporum f. sp. vasinfectum proporcionou plantas menores; os autores relacionaram esse método a um maior nível de infecção do fungo nas sementes, em comparação com o de contato
(SOUSA et al., 2008).

Falcão et al. (2005) observaram respostas insatisfatórias em termos de incidência de doença causada por Sclerotinea sclerotiorum e Sclerotium rolfsii através da utilização do método de inoculação por discos de meio BDA, com micélio, para a contaminação do solo. Esse fato pode estar relacionado à interação do ambiente, hospedeiro e patógeno, ocorrendo alterações nas condições ideais de desenvolvimento do fungo e, por consequência, na sua ação sobre o hospedeiro. A presença do patógeno na semente nem sempre assegura o incremento de doenças no campo, porém todos os patógenos que ali estão são capazes de iniciar o processo da doença (TANAKA; MACHADO, 1985). Os microrganismos podem estar limitados ao tegumento, não caracterizando o processo de infecção e sim a contaminação superficial das sementes (COSTA et al., 2003).

Os sintomas de $C$. lindemuthianum em plântulas de feijão foram observados independentemente do método de inoculação, demonstrando assim que ele é um importante patógeno da cultura, sendo prejudicial no desenvolvimento das plantas.

Geralmente, os diferentes métodos de inoculação são utilizados em trabalhos com resistência de genótipos e com métodos de controle, deste modo, as técnicas não devem comprometer a germinação e precisam garantir níveis de infecção satisfatórios (SOUSA et al., 2008).

De acordo com Rey et al. (2009), o $C$. lindemuthianum apresenta bom potencial de transmissão de semente-plântula de feijão, e este pode variar de $70 \%$ a $80 \%$ independentemente de raças do fungo. Esses autores enfatizam ainda que os valores podem ser considerados altos, e que seu poder de destruição e de disseminação do fungo, aliado à probabilidade de transmissão, é muito importante para a cultura.

De maneira geral, pela emergência satisfatória no estabelecimento de plântulas, pela redução do comprimento de parte aérea e por uma maior incidência de sintomas no hipocótilo, o método de contato direto das sementes ao micélio e aos esporos do fungo com restrição hídrica pode ser o utilizado como adequado para a inoculação do Colletotrichum lindemuthianum 
em sementes de feijão, com o objetivo de infecção das plântulas sem comprometer a emergência. Entretanto, tornam-se necessários mais estudos a fim de se obterem seleções mais criteriosas, uma vez que diversos fatores podem interferir em trabalhos como este, como, por exemplo, ambiente, quantidade e localização do patógeno, pois diferentes genótipos, isolados e formas de inoculação podem interferir nos resultados esperados.

\section{Referências}

ARAÚJO, D. V.; POZZA, E. A.; MACHADO, J. C.; ZAMBENEDETTI, E. B.; CELANO, F. A. O.; CARVALHO, E. M.; CAMARGOS, V. N. Influência da temperatura e do tempo de inoculação das sementes de algodão na transmissibilidade de Colletotrichum gossypii var. cephalosporioides. Fitopatologia Brasileira, Brasília, v. 31, n. 1, p. 35-40, 2006.

BARROCAS, E. N.; MACHADO, J. C.; ALVES, M. C.; CORREAA, C. L. Desempenho de sementes de algodão submetidas à deficiência hídrica e presença de Colletotrichum gossypii var. cephalosporioides. Bioscience Journal, Uberlandia, v. 30, n. 2, p. 421-428, 2014.

BIANCHINI, A.; MARINGONI, A. C.; CARNEIRO, S. M. P. G. Doenças do feijoeiro (Phaseoluls vulgaris L.). In: KIMATI, H.; AMORIM, L.; REZENDE, J. A. M.; BERGAMIN FILHO, A.; CAMARGO, L. E. A. (Ed.). Manual de Fitopatologia. Vol. 2. 4 ed. São Paulo: Editora Ceres, 2005. p. 333-349.

BOTELHO, L. S.; ZANCAN, W. L. A.; MACHADO, J. C.; BARROCAS, E. N. Performance of common bean seeds infected by the fungus Sclerotinia sclerotiorum. Journal of Seed Science, Londrina, v. 35, n. 2, p. 153-160, 2013.

CONAB - COMPANHIA NACIONAL DE ABASTECIMENTO. Acompanhamento da safra brasileira de grãos. Vol. 3 - Safra 2015/16, n. 7 - Sétimo levantamento Levantamento, abril 2016. Disponível em: <http://www.conab.gov.br/OlalaCMS/uploads/ arquivos/16_04_07_09_04_20_boletim_graos_abril_2016_final.pdf>. Acesso em: 06 abril 2016.

CORREA, B. O.; MOURA, A. B.; DENARDIN, N. D.; SOARES, V. N.; SCHÄFER, J. T.; LUDWIG, J. Influência da microbiolização de sementes de feijão sobre a transmissão de Colletrichum Lindemuthianum (Saac e Magn). Revista Brasileira de Sementes, Londrina, v. 30, n. 2, p. 156-163, 2008.

COSTA, M. L. N.; MACHADO, J. C.; GUIMARÃES, R. M.; POZZA, E. A.; ORIDE, D. Inoculação de Fusarium oxysporum f. sp. phaseoli em sementes de feijoeiro através de restrição hídrica. Ciência Agrotecnologia, Lavras, v. 27, n. 5, p. 1023-1030, 2003.

FALCÃO, J. V.; ORILI, F. P.; ÁVILA, Z. R. de; MELLO, S. C. $M$. de. Estabelecimento de metodologia para contaminação de solo com propágulos dos fungos Sclerotinia sclerotiorum e Sclerotium rolfsii, e expressão de doença em soja. Comunicado Técnico. Brasília, 2005. Disponível em: <http://ainfo.cnptia. embrapa.br/digital/bitstream/CENARGEN/27926/1/cot135.pdf $>$. Acesso em: 6 abril 2016.

FERREIRA, D. F. Programa SISVAR. exe: Sistema de análise de variância. Versão 5.0. Lavras: UFLA, 2007.

GALLI, J. A.; PANIZZI, C. de.; VIEIRA, R. D. Resistência de variedades de soja à morte de plântulas causada por Colletotrichum truncatum. Arquivos do Instituto Biológico, São Paulo, v. 74, n. 2, p. 163-165, 2007.

GARCIA, R. A.; JULIATTI, F. C. Avaliação da resistência da soja a Sclerotinia sclerotiorum em diferentes estádios fenológicos e períodos de exposição ao inóculo. Tropical Plant Pathology, Brasília, v. 37, n. 3, p. 196-203, 2012.

JUNGES, E.; MUNIZ, M. F. B.; BASTOS, B. O.; ORUOSKI, P. Biopriming in bean seeds. Acta Agriculturae Scandinavica, Section B - Soil \& Plant Science, Copenhagen v. 66, p. 207-214, 2015.

MATHUR, R. S.; BARNETT, H. L.; LILLY, V. G. Sporulation of Colletotrichum lindemuthianum in culture. Phytopathology, East Lansing, v. 40, n. 1, p. 104-114, 1950.

NAKAGAWA, J. Testes de vigor baseados no desempenho das plântulas. In: VIEIRA, R.D.; CARVALHO, N. M. (Ed.). Testes de vigor em sementes. Jaboticabal: FUNEP, 1994. 164 p.

NAKAGAWA, J. Testes de vigor baseados no desempenho das plântulas. In: KRZYZANOWSKI, F. C.; VIEIRA, R. D.; FRANÇA NETO, J. B. Vigor de sementes: conceitos e testes. Londrina: ABRATES, 1999. p. 2-21.

PEDROSO, D. C.; MENEZES, V. O.; MUNIZ, M. F. B.; PIVETA, G., TUNES, L. V. M. de.; MULLER, J.; MENEZES, N. L. de. Métodos de inoculação de Alternaria alternata e A. dauci em sementes de salsa e sua influência na qualidade fisiológica. Revista Brasileira de Sementes, Londrina, v. 32, n. 3, p. 79-85, 2010.

REIS, G. F.; BACCHI, L. M. A.; GAVASSONI, W. L.; HIRATA, L. M.; PONTIM, B. C. A. Viabilidade de armazenamento de sementes de soja inoculadas com Sclerotinia sclerotiorum em meio com restrição hídrica. Summa Phytopathologica, Botucatu, v. 40, n. 2, p. 168-173, 2014.

REY, M. S.; LIMA, N. B.; SANTOS, J. dos.; PIEROBOM, C. R. Transmissão semente-plântula de Colletotrichum Lindemuthinum em feijão (Phaseolus vulgaris). Arquivos do Instituto Biológico, São Paulo, v. 76, n. 3, p. 465-470, 2009.

SOUSA, M. V.; MACHADO, J. C.; PFENNING, L. H.; KAWASAKI, V. H.; ARAÚJO, D. V.; SILVA, A. A.; MARTINI NETO, A. Métodos de inoculação e efeitos de Fusarium oxysporum f. sp. vasinfectum em sementes de algodoeiro. Tropical Plant Pathology, Brasília, v. 33, n. 1, p. 41-48, 2008.

TANAKA, M. A. S.; MACHADO, J. C. Patologia de sementes. Informe Agropecuário, Belo Horizonte, v. 11, n. 122, p. 40-46, 1985.

VENTUROSO, L. R.; BACCHI, L. M. A; GAVASSONI, W. L; VENTUROSO, L. A. C.; PONTIM, B. C. A; REIS, G. F. Inoculação de Sclerotinia sclerotiorum em sementes de oleaginosas: transmissão e seus efeitos sobre a emergência de plantas. Ciência Rural, Santa Maria, v. 45, n. 5, p. 788-793, 2015. 